\title{
Determination of rational coal and rock pillars height of coal mining under the loose aquifer
}

Wang Jianhu ${ }^{1}$, Shao Mingxi ${ }^{1}$, Shang Yanfeng ${ }^{1}$, Cao Siwen ${ }^{1}$, Zhang Xin ${ }^{1}, \mathrm{Hu}$

Chuanmeng ${ }^{2,3}$

(1. Yangcun mine, Yanzhou Coal Mining Group Co. Ltd, Jining, Shandong2.College of Mining and Safety Engineering, Shandong University of Science and Technology, Qingdao, Shandong 266590 3.National Key Laboratory of Mine Disaster Prevention and Control (Cultivation Base), Qingdao 266590)

\begin{abstract}
An coal mine belongs to the coal mining under medium aquifer, under which there is no stable clay aquifuge. To demonstrate the safety and reliability of coal and rock pillars, study and analysis of the failure and movement feature of overlying strata are conducted in the condition of the mine's geology and coal mining. The mechanism of mining with sand-proof pillars are revealed. The obvious economic benefits have been obtained. The reliable basis is provided for enhancing the mining limit for similar coal mines.
\end{abstract}

Keywords: coal-mining ,aquifer, waterproof pillars, sand-proof pillars.

\section{Mine's hydrogeological feature}

The average thickness of cenozoic loose layers in the coal mine is nearly 140 meters, which is divided into four aquifer and three aquifuge from top to bottom. The first three aquifer and all the aquifuge are distributed widely in all areas of mine, while the fourth aquifer is only distributed in some regions. The first and second aquifer can't directly affect the production of mine, since having much thicker clay aquifuge on their bottom. Meanwhile, the rich water property of the fourth aquifer is weak, which has an slight influence on the safety of mine's production. But the third aquifer's thickness is much thicker and stable distribution. By many pumping tests, whose results are $\mathrm{q}=0.55 \sim 0.711 / \mathrm{s} \bullet \mathrm{m}$, $\mathrm{k}=1.96 \sim 11.18 \mathrm{~m} / \mathrm{d}$ and $\mathrm{T}=79.02 \sim 216.04$ $\mathrm{m} 2 / \mathrm{d}$, the third aquifer belongs to a middle water-rich layer. There is a clay aquifuge below the third aquifer called the third aquifuge, its thickness is distributed unevenly and is less than 5 meters under general conditions. In the north mine field, the third aquifer directly locates on coal measure strata, even lacking it in a part of region, which is resulted in losing a water-resisting function. The third aquifer is a mainly water filling source threatened the mine's safety and production in some regions, such as thinner clay regions and bottom sticky area especialiy the north regions of the mine.

2. The feature of overlying strata with enhancing the mining limit

2.1 The development characteristics and heights of overlying strata's caving zone and fracture zone "two zones".

To research on the feature of overlying strata with enhancing the mining limit, considering this mine's geological conditions, the research group has accomplished 20 drilling used to detect the heights of "two zones" in the mining working faces, including two blasting faces and three fully-mechanized faces, and conducted scientific observation 
tests. The mining geological conditions of trial faces and the lithologic features of roof and floor are shown in Tab.1 and Tab.2.No.6 Working Face is located in the shallow areas of mine field, and belongs to coal mining under the condition of medium-hard overlying rocks with water-proof pillars, the height of which is 54.0 70.0 meters. No.2, No.3,
No.4 and No.5 Working Face are both located in the shallow areas of mine field too, but they belong to coal mining under the condition of weaker overlying rocks closed to weathering zone with sandproof pillars, their sand-proof pillars' heights are 13.3 meters, 21.8 meters, 19.5 meters and 28.0 meters respectively.

Table 1 The geological and mining conditions of trial working faces

\begin{tabular}{|c|c|c|c|c|c|}
\hline \multirow{2}{*}{$\begin{array}{c}\text { Working } \\
\text { face }\end{array}$} & \multirow{2}{*}{$\begin{array}{l}\text { Average } \\
\text { thickness of } \\
\text { mining }\end{array}$} & \multirow{2}{*}{$\begin{array}{c}\text { Dip } \\
\text { angle }\end{array}$} & \multirow{2}{*}{$\begin{array}{l}\text { Mining } \\
\text { technology }\end{array}$} & \multicolumn{2}{|c|}{ The range of working face } \\
\hline & & & & $\begin{array}{c}\text { The length } \\
\text { of face }\end{array}$ & $\begin{array}{c}\text { The advancing } \\
\text { length }\end{array}$ \\
\hline No.1 & 2.18 meters & $5^{\circ}$ & Blasting mining & 160 meters & 500 meters \\
\hline No. 2 & 1.8 meters & $5^{\circ} \sim 7^{\circ}$ & Blasting mining & 200 meters & 210 meters \\
\hline No.3 & 2.9 meters & $5^{\circ} \sim 7^{\circ}$ & $\begin{array}{c}\text { Fully- } \\
\text { mechanized }\end{array}$ & 147 meters & 800 meters \\
\hline No.4 & 3.0 meters & $3^{\circ} \sim 5^{\circ}$ & $\begin{array}{c}\text { Fully- } \\
\text { mechanized }\end{array}$ & 147 meters & 1060 meters \\
\hline No. 5 & 3.0 meters & $5^{\circ} \sim 6^{\circ}$ & $\begin{array}{c}\text { Fully- } \\
\text { mechanized }\end{array}$ & 137 meters & 950 meters \\
\hline
\end{tabular}

Table 2 The lithological feature of the roof and floor in the trial working faces

\begin{tabular}{|c|c|c|c|c|c|}
\hline \multirow{2}{*}{$\begin{array}{c}\text { Working } \\
\text { face }\end{array}$} & \multicolumn{2}{|c|}{ Roof's lithology } & \multirow{2}{*}{$\begin{array}{c}\text { Floor's } \\
\text { lithology }\end{array}$} & $\begin{array}{c}\text { Overlying } \\
\text { strata's } \\
\text { lithology }\end{array}$ & $\begin{array}{c}\text { Geological } \\
\text { structure }\end{array}$ \\
\cline { 2 - 5 } No.1 & Mudstone & Sandstone & Sandstone & Medium-hard & Simple \\
\hline No.2 & Mudstone & Siltstone & Siltstone & $\begin{array}{c}\text { Weathered- } \\
\text { weak }\end{array}$ & Common \\
\hline No.3 & $\begin{array}{c}\text { Mainly } \\
\text { mudstone }\end{array}$ & $\begin{array}{c}\text { Mainly } \\
\text { mudstone }\end{array}$ & Mudstone & $\begin{array}{c}\text { Weathered- } \\
\text { weak }\end{array}$ & Simple \\
\hline No.4 & $\begin{array}{c}\text { Mainly } \\
\text { mudstone }\end{array}$ & $\begin{array}{c}\text { Mainly } \\
\text { mudstone }\end{array}$ & $\begin{array}{c}\text { Fine sandstone } \\
\text { and siltstone }\end{array}$ & $\begin{array}{c}\text { Weathered- } \\
\text { weak }\end{array}$ & Simple \\
\hline No.5 & Mudstone & Sand-shale & Siltstone & $\begin{array}{c}\text { Weathered- } \\
\text { weak }\end{array}$ & Simple \\
\hline
\end{tabular}

Using various methods, such as the method of consuming flushing liquid and Water Level Change Curve Method, have analyzed observation results roundly, then obtained the development feature of caving zone and water flowing fractured zone, which looks like a saddle that is shown as lower middle parts and higher both sides. No.1 face unweathered, its the general height of caving zone is 9.06 14.2 meters, the ratio of caving zone's height and mining thickness is 4.16 6.64. The general height of water flowing fractured zone is 17.32 40.85 
meters, the ratio of fractured zone's height and mining thickness is 9.60 19.45.The caving zone's heights of a blasting face (No. 2)and three large mining height fully-mechanized faces(No.3, No.4and No.5) are $2.60 \sim 3.64$ meters and 1.66 8.80 meters respectively. The ratios of caving zone's height and mining thickness are 1.44 1.92 and 0.55 2.84 separately. Furthermore, heights of water flowing fractured zone are 11.45 15.01 meters and 9.12 27.80 meters. The ratios of fractured zone's height and mining thickness are 5.73 7.90 and 2.94 9.27 separately.

\subsection{The failure and movement feature of overlying strata.}

Based on the further analysis of "two zones' heights" and other observed results finds that, with the reducing of water-proof pillars under water, when coal mining is in close proximity to the bedrock weathering zone, the damage and movement of overlying strata above the mining area have lots of differences and obvious characteristics comparing with coal mining is in the not weathering area. The comparisons of the ratio of mining thickness and the heights of caving zone and water flowing fractured zone in trial faces are listed in Tab.3.

As Table. 3 shown, in similar geological mining conditions, when mining after enhancing the mining limit and reducing water-proof pillars, the height of caving zone and height of water flowing fractured zone is greatly reduced, and their mining thickness ratio is reduced significantly. Using the sand-proof pillars of a blasting face (No. 2)and three large mining height fully-mechanized faces(No.3, No.4, No.5), their heights of caving zones are $33 \% \sim 35 \%$ of No.1 blasting face which mines in accordance with the original limit and water-proof pillars, namely the height of caving zone is reduced by $65 \% \sim 67 \%$.And their heights of water flowing fractured zones are $34 \% \sim 43 \%$ of No.6 working face equivalent to be reduced by $57 \% \sim 66 \%$. In this case, reducing water-proof pillars and using the sand-proof pillars mining, the working faces' average ratio of caving zone's height and mining thickness is 1.770 , which of that part area of fullymechanized faces is only 0.55 0.81. Its average ratio of fractured zone's height and mining thickness is 6.056, which of that part area of fully-mechanized faces is only 4. Obviously, these results at least reduce by about $50 \%$ comparing with the numericals that measured and calculated by the empirical equations under conditions of general medium hard and medium hard partial soft and weak strata at home.

Table 3 The comparisons of the ratio of mining thickness and the heights of caving zone and water flowing fractured zone in trial faces

\begin{tabular}{|c|c|c|c|c|c|c|c|}
\hline \multirow{3}{*}{\multicolumn{2}{|c|}{$\begin{array}{l}\text { Comparison } \\
\text { contents }\end{array}$}} & \multirow{2}{*}{\multicolumn{2}{|c|}{$\begin{array}{c}\text { the original mining limit } \\
\text { No.1 blasting face }\end{array}$}} & \multicolumn{4}{|c|}{ Mining after enhancing mining limit } \\
\hline & & & & \multicolumn{2}{|c|}{ No. 2 blasting face } & \multicolumn{2}{|c|}{$\begin{array}{l}\text { Fully-mechanized } \\
\text { faces } \\
\text { No.3, No.4, No.5 } \\
\end{array}$} \\
\hline & & value & $\begin{array}{l}\text { Compariso } \\
\text { n value, } \%\end{array}$ & value & $\begin{array}{c}\text { Comparison } \\
\text { value, } \%\end{array}$ & value & $\begin{array}{c}\text { Comparison } \\
\text { value, } \%\end{array}$ \\
\hline \multirow[t]{2}{*}{$\mathrm{I}_{\mathrm{s}}$} & $\begin{array}{c}\text { variation } \\
\text { range } \\
\end{array}$ & $4.16-6.46$ & 100 & $\begin{array}{l}1.44- \\
1.92 \\
\end{array}$ & $34.6-29.7$ & $\begin{array}{l}0.55- \\
2.84 \\
\end{array}$ & $13.2-44.0$ \\
\hline & average & 5.185 & 100 & 1.719 & 33.1 & 1.821 & 35.1 \\
\hline \multirow[t]{2}{*}{$I_{d}$} & $\begin{array}{c}\text { variation } \\
\text { range } \\
\end{array}$ & $\begin{array}{l}9.60- \\
19.45 \\
\end{array}$ & 100 & $\begin{array}{l}5.73- \\
7.90 \\
\end{array}$ & $59.1-40.6$ & $\begin{array}{l}2.94- \\
9.27 \\
\end{array}$ & $30.6-47.7$ \\
\hline & average & 15.715 & 100 & 6.697 & 42.6 & 5.415 & 34.4 \\
\hline
\end{tabular}


In this table, $I_{s}$ is the ratio of caving zone's height and mining thickness; $I_{d}$ is the ratio of fractured zone's height and mining thickness.

\section{The feasibility analysis of mining with sand-proof pillars}

By comprehensively analyzing according to the test datum of vast and all kinds of rock properties and other test results, further revealing mining conditions and mechanism of reducing water-proof pillars and setting up sand-proof pillars. As the hydrological prospecting test shown, degree and depth of bedrock weathering are uniform in a specific range. Especially in a working face range, the thickness of the bedrock weathering zone is pretty much identical. The general thickness is 20 25 meters, while the strong weathering portion is about 10 meters. The test results of rocks which located in each horizon under the bedrock surface show that with the increase of the weathering degree, mechanical strength of rocks will lower. However, the moisture content of rock strata increases gradually from coal seam roof up. The influence of the rock strength by weathering degree is in Tab.5. Through the analysis of the rock ore wafer of powder sandstone and mid-fine sandstone, which is located in the strongly weathering zone under the bedrock surface, shows that many of them are argillaceous cementing, minerals contained feldspar change clayization by strong weathering, especially mudstone and the bauxitic mudstone disintegrated rapidly and become argillization after water erosion.

Because weathered rock strata in this mine is mainly composed of relatively weak argillaceous rock and powder sandstone, which has a number of properties ,such as low strength, large plastic, strong ability of resisting deformation, and rocks tend to argillization and primary fracture and mining-induced fracture are easily closed and pressed. It can fully inhibit the height development of the caving zones, development degree of fracture, and fracture's connectivity and osmosis water. Meanwhile it has strong water-retardation effect, even forms the natural barrier in strong weathering section, it has a strong ability to retard water so that prevents upper water and sand flowing down into mining space. So the damage and movement features of overlying strata create conditions for safety mining which is in condition of reducing water-proof pillars and setting sand-proof pillars.

Table 4 The strong weathering zone mudstone's disintegration rate

\begin{tabular}{|c|l|l|l|l|l|}
\hline \multirow{2}{*}{$\begin{array}{c}\text { Sampling } \\
\text { hole }\end{array}$} & $\begin{array}{c}\text { Depth under } \\
\text { bedrock } \\
\text { surface }\end{array}$ & Lithology & \multicolumn{3}{|c|}{ Devolution velocity/\% } \\
\cline { 4 - 6 } & 0.50 & Mudstone & 12.01 & 22.68 & 34.10 \\
\hline \multirow{4}{*}{$\begin{array}{c}\text { Post-mining } \\
\text { K5 }\end{array}$} & 1.00 & Mudstone & 10.91 & 21.76 & 30.18 \\
\cline { 2 - 6 } & 1.80 & Mudstone & 10.18 & 25.39 & 38.21 \\
\cline { 2 - 6 } & 3.03 & Mudstone & 17.32 & 31.96 & 42.96 \\
\cline { 2 - 6 } & 3.80 & Mudstone & 16.24 & 28.20 & 39.32 \\
\hline \multirow{4}{*}{$\begin{array}{c}\text { Pre-mining } \\
\text { K6 }\end{array}$} & 2.80 & Mudstone & 4.15 & 7.73 & 12.06 \\
\cline { 2 - 6 } & 3.50 & Mudstone & 4.05 & 9.05 & 14.41 \\
\cline { 2 - 6 } & 6.00 & Mudstone & 3.71 & 6.09 & 8.47 \\
\cline { 2 - 6 } & 8.40 & Mudstone & 1.89 & 2.81 & 3.62 \\
\hline
\end{tabular}


Table 5 The weathering degree's influence on the strength of rock

\begin{tabular}{|c|c|c|c|c|c|c|}
\hline $\begin{array}{c}\text { Hole } \\
\text { number }\end{array}$ & $\begin{array}{c}\text { Depth under } \\
\text { bedrock } \\
\text { surface }\end{array}$ & Lithology & $\begin{array}{c}\text { Compressive } \\
\text { strength } \\
/ \mathrm{MPa} \\
\end{array}$ & $\begin{array}{c}\text { Moisture } \\
\text { content } \\
/ \% \\
\end{array}$ & $\begin{array}{c}\text { Weathering } \\
\text { degree }\end{array}$ & Note \\
\hline \multirow{2}{*}{ K1 } & 4.91 & $\begin{array}{c}\text { Fine } \\
\text { sandstone }\end{array}$ & 9 & 2.00 & $\begin{array}{c}\text { Strong } \\
\text { weathering }\end{array}$ & \multirow{2}{*}{$\begin{array}{l}\text { Post- } \\
\text { mining } \\
\text { hole }\end{array}$} \\
\hline & 5.41 & $\begin{array}{c}\text { Fine } \\
\text { sandstone }\end{array}$ & 18 & 2.33 & Weathering & \\
\hline \multirow[t]{2}{*}{$\mathrm{K} 2$} & 6.5 & $\begin{array}{c}\text { Medium } \\
\text { sandstone }\end{array}$ & 2.7 & 2.70 & $\begin{array}{c}\text { Strong } \\
\text { weathering }\end{array}$ & \multirow{2}{*}{$\begin{array}{l}\text { Post- } \\
\text { mining } \\
\text { hole }\end{array}$} \\
\hline & 13.57 & Mudstone & 13.5 & 2.82 & Weathering & \\
\hline \multirow[t]{2}{*}{$\mathrm{K} 3$} & 12 & $\begin{array}{c}\text { Medium } \\
\text { sandstone }\end{array}$ & 5.1 & 6.97 & $\begin{array}{c}\text { Strong } \\
\text { weathering }\end{array}$ & \multirow{2}{*}{$\begin{array}{l}\text { Post- } \\
\text { mining } \\
\text { hole }\end{array}$} \\
\hline & 16 & Mudstone & 27.9 & 4.04 & Weathering & \\
\hline \multirow{4}{*}{ K4 } & 13.35 & Mudstone & 10.4 & 3.73 & $\begin{array}{c}\text { Strong } \\
\text { weathering }\end{array}$ & \multirow{4}{*}{$\begin{array}{l}\text { Pre- } \\
\text { mining } \\
\text { hole }\end{array}$} \\
\hline & 19.45 & Mudstone & 19.3 & 3.92 & Weathering & \\
\hline & 26.55 & Mudstone & 22.6 & 2.54 & Weathering & \\
\hline & 27.95 & Mudstone & 25.1 & 1.63 & Weathering & \\
\hline
\end{tabular}

The mining that large reducing waterproof pillars and setting sand-proof pillars has achieved over the years. It realizes safety mining from beginning to end without water gushing and even without water spraying and dropping in a dozen testing faces. The heights of most face coal rock pillars only are 13 20 meters, there are only 2 meters from the caving fracture's top to the loose bed, in this condition, the stope still has not occurred water spraying phenomenon. A large number of repeated exploration practices have proved that realizing mining without water running and even without water gushing and spraying only needs to take measures to prevent strata caving, even if the coal rock pillars height is small and is similar to caving-prevention pillars' height.

\section{Determination of reasonable safety sand-proof pillars' height}

The height of sand-proof pillars are made of caving zone's height and the thickness of covering layer, as shown in equation 1.That allows the water flowing fractured zone entering to upper water while the caving zone doesn't.

$$
H_{s}=I_{s} \bullet m+h_{f}
$$

In this equation, $H_{s}$ is sand-proof pillars' height, $\mathrm{m} ; I_{s}$ is the ratio of caving zone's height and mining thickness; $m$ is mining thickness, $\mathrm{m}$; $h_{f}$ is covering layers' height, m.

According to the detection test of the strata damage and "two zones" heights, The mine's a blasting face (No.2)and three large mining height fullymechanized faces(No.3, No.4, No.5) are closed to the weathering zone, their heights of caving zone are 1.66 8.80 meters, the maximum is 8.80 meters. The ratio of caving zone's height and mining thickness is $0.55 \sim 2.84$, the maximum is 2.84. According to the maximum ratio of caving zone's height and mining thickness $I_{s}$ is 2.84,calculating the height of sand-proof pillars $H_{S}$ respectively are: 
(1) If mining thickness of the fullymechanized face $\mathrm{m}$ is 3.0 meters, covering layer thickness hf is 8 meters, then Hs is about 17 meters.(2) If mining thickness of the blasting face $\mathrm{m}$ is 2.2 meters, covering layer thickness hf is 6 meters, then Hs is about 12 meters.

According to the calculation of the mine's measured parameters, the pillars setting heights of blasting face and fullymechanized face are respectively 12 meters and 17 meters, these can prevent loose layers' water and sand collapsing, and realize safe production.

The sand-proof pillars general heights of the blasting face and fully-mechanized face should be enhanced to 15 meters and 20 meters respectively to ensure safety in mine production, and try not to destroy structure and water-resisting property of strong bedrock weathering zone and adapt to the requirements of other geological mining conditions change. When stoping is in the fault fracture zone and strong rich water area, that also should increase coal rock pillars height and take measures to prevent strata being produced unbalanced damage.

\section{Conclusion}

The realization of the mining with sandproof pillars under medium aquifer is the cause that bedrock suffered from weathering and strong weathering occurs structure and component variation, has dual function of stopping above the third aquifer's water vertical infiltration and restraining the development of mininginduced fractures. The study has important guiding significance for mining water and sand proof pillars contained and other similar conditions of the mining under the loose aquifer.

\section{References}

[1] National Bureau of Coal Industry. Building, water, railway, main well leaving coal pillar and unexploited coal regulation[M]. Beijing: China Coal Industry PublishingHouse, 2000.

[2] Xu Yanchun, Li Zhenhua, Jia Anli,et al. Site Measurement and Analysis on Failure Height of Overburden Strata Under Thick Loose Alluvium and Thin Bedrock $[\mathrm{J}]$. Coal Science and Technology, 2010,38(7):21-23.

[3] Yang Weifeng. Analysis of the Mining Failure Regularity and Safety Mining in Thin Bedrock[J]. Journal of Engineering Geology, 2008, 16(Suppl.): 570-573.

[4] Yang Weifeng. Analysis of the mining failure regularity and safety mining of the weak and weathered composite roof, China Ming Magazine 2008,17(5):61-67. 